\title{
Atendimento Domiciliar em Saúde Mental ao usuário do CAPS
}

\author{
Francisca Silva de Alencar ${ }^{1}$; Lúcia Vanda T. Freitas Cavalcante ${ }^{2}$; Marcela de Souza Lima ${ }^{3}$; \\ Nicácia Souza Oliveira ${ }^{4}$; Gislene Farias de Oliveira ${ }^{5}$
}

\begin{abstract}
Resumo: A saúde mental é tão importante como à saúde física para a comodidade dos indivíduos e das sociedades. Não obstante, só uma pequena minoria de pessoas que apresentam perturbações mentais e comportamentais está a receber tratamento. No estudo faz uma análise do atendimento domiciliar em saúde mental ao usuário do CAPS. Tem por objetivo Analisar as percepções familiares sobre o cuidado prestado pelo CAPS ao usuário em situação de cárcere privado no ambiente domiciliar. Trata-se de um estudo descritivoexploratório com uma abordagem qualitativa, realizada com o universo de 07 usuários do CAPS do município de Iguatu-CE. Para a coleta de dados aplicou-se uma entrevista semi-estruturada em março e abril de 2011 com anuência escrita dos participantes. Os dados foram categorizados, analisados e interpretados. Dos 07 entrevistados, obtiveram-se os seguintes resultados: com relação à perfil clinico dos pacientes, todos tiveram inicio súbito e com uma tristeza prolongada e na vida adulta, apenas 1 já nasceu com esse transtorno. Onde todos os familiares sentiram resistência a aceitar a patologia do paciente. Os entrevistados revelaram ter consciência que é necessário um acompanhamento melhor, porém relataram muitas dificuldades. Em relação ao atendimento do Caps a esses pacientes, os participantes da pesquisa relataram uma enorme satisfação, mas não é o suficiente para uma assistência completa. Percebeu - se que as visitas domiciliares são de extrema importância para esses pacientes como também para a família é preciso trabalhar melhor as visitas como também orientar os familiares sobre os cuidados a serem realizados com esses pacientes inserindo - os no convívio familiar e social.
\end{abstract}

Palavras Chaves: Saúde Mental; Atendimento domiciliar; CAPS.

\section{Homecare in Mental Health to the CAPS users.}

\begin{abstract}
Mental health is as important as physical health for the convenience of individuals and societies. Nevertheless, only a small minority of people who have mental and behavioral disorders are receiving treatment . This study is an analysis of homecare in mental health to the user of CAPS. It aims to analyze family perceptions about the care provided by the CAPS to users in the home environment . This is a descriptiveexploratory study with a qualitative approach, performed with the universe of 07 CAPS users of the municipality of Iguatu - CE . For data collection a semi-structured interview was applied in March and April 2011 with written consent of the participants. The data were categorized, analyzed and interpreted. Of the 07 respondents, we obtained the following results regarding the clinical profile of patients: all had sudden onset and a prolonged sadness in adulthood, only one was born with this disorder. Also, all family members felt resistance to accept the condition of the patient. Respondents revealed to realize that better monitoring is needed, but reported many difficulties. In relation to Caps assistance to these patients, research participants reported great satisfaction, but it is not enough for a complete service. Is was realized that home visits are very important to these patients as well as the need to work better the visits to also guide families about the care to be performed with these patients, introducing them in the family and social life.
\end{abstract}

Key Words : Mental Health, Homecare, CAPS .

\footnotetext{
${ }^{1}$ Enfermeira pela Universidade Regional do Cariri - URCA, Especialista em Saúde da Família pela Faculdade São Francisco da Paraíba - FASP, Professora da Universidade Regional do Cariri. E-mail:silvia.rami@ hotmail.com

${ }^{2}$ Enfermeira pela Universidade Federal da Paraíba, Mestrado pela Universidade Estadual do Ceará, Professora da Universidade Regional do Cariri E-mail: lvtfreitas@yahoo.com.br

${ }^{3}$ Marcela de Souza Lima , Enfermeira pela Universidade Regional do Cariri - Iguatu, E-mail:marcelasouza@hotmail.com

${ }^{4}$ Nicácia Souza Oliveira, Enfermeira pela Universidade Regional do Cariri - URCA, Especialista em Saúde Coletiva pela Faculdade São Francisco da Paraíba - FASP, Professora da Universidade Regional do Cariri. E-mail:nicaciaoliveira@hotmail.com ${ }^{5}$ Professora da Universidade Federal do Cariri. Pós Doutoranda pela Faculdade de Medicina do ABC. São Paulo - SP. Email: gislenefarias@gmail.com,
} 
Introdução

A saúde mental é tão importante como à saúde física para a comodidade dos indivíduos e das sociedades. Não obstante, só uma pequena minoria de pessoas que apresentam perturbações mentais e comportamentais estão a receber tratamento. Avanços na neurociência e na medicina do comportamento já mostraram que, como muitas doenças físicas, estas perturbações resultam de complexas interações psicológicas e sociais. Embora ainda haja muito por aprender, já temos o conhecimento e a capacidade necessária para reduzir o peso que as perturbações mentais e comportamentais representam em todo o mundo (OMS, 2002).

A política de saúde mental no Brasil é uma possibilidade recente, conquistada a partir do processo de reforma psiquiátrica. A assistência psiquiátrica brasileira apareceu da função saneadora dos primeiros hospícios, assumindo um papel excludente. Foi criada em 1890 sob administração pública da Assistência Médico-Legal aos Alienados, de caráter predominantemente asilar. Só em 1978 começa a ser constituído o movimento de reforma psiquiátrica brasileiro, ganhando expressão o Movimento dos Trabalhadores de Saúde Mental (MTSM), e de inicio defendiam o fim do modelo hospitalocêntrico (BORGES e BAPTISTA, 2008).

Outro dispositivo que teve enorme crescimento em saúde mental foram os Centros de Atenção Psicossocial (CAPS), configuraram - se como a possibilidade da organização de uma rede substitutiva ao hospital psiquiátrico no país e têm como função prestar atendimento clínico em regime de atenção diária, evitando assim as internações e promovendo a inserção social das pessoas com transtornos mentais. Hoje existem aproximadamente 689 caps, representando $64 \%$ dos recursos do Ministério da Saúde para a saúde mental (ASSIS et al, 2009).

O crescimento do atendimento domiciliar no Brasil é recente, estando no ápice na ultima década. A propagação desta modalidade de prestação de serviços ocorre tanto no setor privado quanto no setor público, fazendo parte de discussão das políticas de saúde que, pressionadas pelos altos custos das internações hospitalares, buscam saídas para uma melhor utilização dos recursos financeiros (FLORIANI e SCHRAMM, 2004).

Para o portador de doença mental o atendimento domiciliar é essencial para a manutenção da sua saúde, pois o paciente é tratado estando em contato com o meio social e sua família fazendo assim com que aconteça a colaboração de todos profissionais, paciente e família, para que todos vejam diariamente a evolução do quadro.

A partir desta motivação surgiu a seguinte questão de pesquisa: "Quais as percepções familiares sobre o cuidado prestado pelo CAPS ao usuário em situação de cárcere privado no ambiente domiciliar?"

Id en line Revista de Psicologia. Ano 7, No. 21, Novembroo/2013 - ISSN 1981-1179.

Edição eletrônica em http://idonline.emnuvens.com.br/id 
http://idonline.emnuvens.com.br/id

ISSN on-line: 1981-1179

O interesse de investigar sobre a temática surgiu a partir da existência de pacientes em situação de cárcere mesmo com o fácil acesso aos dispositivos de saúde mental. Sabe - se que hoje a situação do portador de transtorno mental teve um grande avanço, com a melhora do acesso aos serviços de saúde mental, porém ainda existem casos de violência, negligência e cárcere privado com esses pacientes. Buscando explorar o motivo que leva a família a manter o paciente em cárcere privado e encorajar os familiares a colaborarem com o tratamento e as visitas do caps, é que desejamos desenvolver a pesquisa.

O presente estudo tem como finalidade ouvir os familiares dos pacientes e avaliar o atendimento de saúde, realizado pela equipe do CAPS III Iguatu, e qual a sua percepção do serviço acerca de encorajar os familiares a sair dessa situação.

\section{Método}

Trata-se de uma pesquisa de natureza exploratória, descritiva, com abordagem qualitativa. Conforme Minayo (2008), o método qualitativo é o que se aplica ao estudo da história, das relações, das representações, das crenças, das percepções e das opiniões, produtos das interpretações que os humanos fazem a respeito de como vivem, constroem seus artefatos e a si mesmos, sentem e pensam. Tem por objetivo trazer dados, indicadores e tendências observáveis ou produzir modelo teórico de alta abstração com aplicabilidade prática.

A pesquisa foi realizada no município de Iguatu, com o universo existente, 06 participantes do sexo masculino e feminino, onde foi utilizado como técnica para coleta de dados uma entrevista semi-estruturada.

Os sujeitos da pesquisa foram os familiares ou cuidadores dos pacientes com transtorno mental que vivem em cárcere privado acompanhados pelos profissio Utilizou - se para análise de dados a Técnica de Análise de Conteúdo de Bardin (2002, p. 38), no qual diz a autora ser "[...] um conjunto de técnicas de análise das comunicações que utiliza procedimentos sistemáticos e objetivos de descrição do conteúdo das mensagens".

As entrevistas foram gravadas, ouvidas e transcritas na íntegra e após o estudo apagadas preservando a identidade do sujeito.

A pesquisa obedeceu a Resolução 196/96 do Conselho Nacional de Saúde/ Ministério da Saúde (CNS/ MS) sobre pesquisa envolvendo seres humanos. Os sujeitos da pesquisa serão respeitados quanto a sua autonomia e dignidade, será mantido o anonimato e será permitido retiraremse da pesquisa a qualquer momento (BRASIL, 1996).

Id en line Revista de Psicologia. Ano 7, No. 21, Novembroo/2013 - ISSN 1981-1179

Edição eletrônica em http://idonline.emnuvens.com.br/id 


\section{Análise e Discussão Dos Dados}

A pesquisa propôs uma análise da percepção dos familiares sobre o cuidado prestado pelo CAPS ao usuário em situação de cárcere privado no ambiente domiciliar.

Nos itens abaixo se apresenta os dados referentes ao sexo, idade, estado civil, zona urbana ou rural, escolaridade e renda dos entrevistados como forma de caracterizar o universo da pesquisa em questão.

A idade dos entrevistados envolvidos na pesquisa está compreendida entre 27 e 73 anos, fato esse que mostra que as pessoas que convivem com o paciente são acima de 25 anos com maturidade para lidar com a situação e compreender as dificuldades enfrentadas por toda família.

A analise das características sociais dos participantes mostrou que a 4 moravam na zona rural, é um fator com uma certa importância devido a um dos objetivos do trabalho que é avaliar o atendimento domiciliar executado pelo CAPS.

Das 07 pessoas entrevistadas 05 possuíam o $1^{\circ}$ grau incompleto 01 pessoa possui o $1^{\circ}$ grau completo, 01 era analfabeto.

Quanto à situação empregatícia, 03 dos entrevistados eram agricultores, 03 donas do lar, normalmente em virtude a dedicação ao lar, a família e ao paciente, onde 2 eram aposentadas e 1 pensionista. Existia 1 que trabalhava com artesanato em sua própria casa não podendo trabalhar fora pela disponibilidade de ter que cuidar do paciente com transtorno mental que vive em cárcere.

Nenhum dos entrevistados ganha menos de um salário mínimo, 3 ganham entre 1 a 2 salários mínimo, 4 ganham de 2 a 3 salários mínimo, por ter conseguido aposentar o paciente com transtornos.

A análise das características sociais dos entrevistados estudados mostrou que 4 eram do sexo feminino, e 3 do sexo masculino, 1 pessoa era solteira, 2 pessoas eram viúvas. Não foi encontrada nenhuma relação entre o gênero e o estado civil com os dados obtidos na pesquisa.

\section{Categorias Temáticas}

\section{O perfil clínico dos usuários do CAPS em situação de cárcere privado.}

- Subcategoria 1- Início da doença

Observando as respostas obtidas, notou-se que alguns dos sujeitos começaram com uma tristeza inesperada e sem explicação já outros eram patologias congênitas e descoberto na segunda infância como dizem nas falas a seguir: 
Bom minha filha ele trabalhava e certo dia chegou em casa, ele veio aqui e disse a mim que o gerente deu um grito nele tão grande e ele se sentiu muito pequeno do tamanho de um caroço de feijão (...). Daí pra frente foi só tristezas (Vermelho).

Ele foi ficando triste, não queria mais trabalhar e triste com dor de cabeça e muito triste chorando e via as coisas (...) (Branco).

Quando os cuidadores familiares foram indagados sobre o que fizeram no início da doença relataram o seguinte:

(...) fomos pra o regional sem querer acreditar, depois levei ainda 2 vezes no médico da firma mas ele passava uns remédio e num dizia o que era aí depois levei pra o Caps (...) (Vermelho).

É sempre difícil iniciar o tratamento com o paciente com transtorno mental, dos 7(sete) entrevistados apenas $1(\mathrm{um})$ relatou ter ido logo diretamente ao Caps. O modelo que antecedeu a reforma psiquiátrica ainda vigora nos pensamentos de alguns familiares e eles passam a temer que o paciente fique internado, já outros acham que deveriam ficar internados sempre, evitando assim correr risco e tirando de cima de si a responsabilidade de cuidador.

\section{Cuidado prestado por familiares aos pacientes.}

A Categoria em questão revelou analisar, dos participantes quais cuidados eles tem com o paciente que vive em cárcere privado e obtivemos as seguintes respostas:

Ela já passou um período sem se alimentar e é mais com isso alimentação mesmo e os remédio na hora certa (...) (Azul).

Ah minha filha aqui o maior cuidado mesmo é pra não sair de casa, porque o povo aí na rua gosta muito de judiar dele (...) (Verde).

Cuidado de ele ta limpo e de comer e ter alguma coisa pra fazer (...) (Roxo).

Mudanças nas rotinas familiares e atividades como ir e vir do trabalho ou escola, cuidados pessoais de asseio/higiene, realização de tarefas corriqueiras dentro de casa ou no quintal são dificuldades encontradas pelos pacientes com transtorno mental, A incapacidade para a realização dessas tarefas domésticas simples e o desemprego acomete a maioria dos portadores de doenças crônicas e de curso prolongado, abrangendo a doença mental (KOGA, FUREGATO, 2002). 
- Subcategoria 2 - Dificuldades enfrentadas pelos familiares.

Os Familiares também destacam as dificuldades enfrentadas com esses pacientes com transtorno ao longo da descoberta até hoje.

A maior dificuldade mesmo é porque não podemos sair de casa porque temos que cuidar dela (...) (Azul).

Minha filha aqui eu passo necessidade pra da tudo a ele, o que falta mesmo é o dinheiro (...)(Vermelho).

Tornar-se cuidador de um paciente psiquiátrico pode gerar uma enorme sobrecarga, porque constitui um rompimento no ciclo esperado de vida, que pressupõe que pessoas adultas sejam independentes. Além disso, tornar-se cuidador de um paciente psiquiátrico requer que os familiares coloquem suas necessidades e desejos em segundo plano e reorganizem sua vida em função das necessidades do paciente (BARROSO; BANDEIRA; NASCIMENTO, 2007).

\section{Ações realizadas pelo CAPS nas visitas domiciliares.}

Nesta categoria estão expressas as opiniões dos usuários em relação ao atendimento domiciliar realizado pela equipe do CAPS. Quando questionamos como era o tratamento do CAPS com esses pacientes eles relataram que:

Elas são boas, elas vêm pra ajudar a gente eu gosto muito se não fosse elas não existia tratamento pra essas doenças não (...) (Azul).

Não tenho o que falar delas, são muito boas, vem deixam remédios, organizam botam a hora dele tomar conversam (...) (Vermelho).

Olha aí como ele ta vê a pressão se ta boa conversam aí com ele só essas coisas mesmo (...) (Roxo).

O CAPS é um serviço substitutivo de atenção em saúde mental que tem demonstrado efetividade na substituição da internação de longos períodos, por um tratamento que não isola os pacientes de suas famílias e da comunidade, mas que envolve os familiares no atendimento com a atenção necessária, ajudando na recuperação e na reintegração social do indivíduo com sofrimento psíquico (SCHRANK; OLSCHOWSKY, 2008).

Quando os entrevistado foram abordados como eram as visitas descreveram da seguinte forma:

Elas chegam sentam, perguntam como ta, como foi esses últimos meses, diz as coisas pra gente fazer, depois vão La ver ela e conversam com ela (Azul). 
Conversam, mede a pressão, pega na mão dele e puxa assunto La com ele, chamam o nome dele e ele vem correndo (...) (Verde).

Elas dão o remédio falam com ela e perguntam umas coisas, como ela ta o que ta comendo se ta precisando de alguma coisa, diz pra gente cuidar dela direito (Rosa).

Fica comprovado com as falas que a equipe que faz a visita domiciliar já desenvolveu um vínculo com o paciente e a família, tratando - os como um ser que necessita de cuidados e atenção. $\mathrm{O}$ incentivo dessas visitas é fazer com que esses pacientes sintam - se importantes e cuidados no ambiente familiar, uma vez que o cárcere traz consigo uma sensação de estarem presos por serem pessoas anormais.

Quando fomos finalizar a entrevista indagamos com o familiar se seria possível esse paciente viver sem está no cárcere e foi notório que todas as respostas foram negativas:

Não, porque ele foge e não sabe mais voltar (...) (Vermelho).

De jeito nenhum! Ele é violento e eu tenho muito medo (...) (Amarelo).

Apesar de todos os relatos que os pacientes são importantes na vida dos familiares, sempre existe o estigma do portador de transtorno mental perigoso, nocivo e insensível. A reforma psiquiatra atualmente já mudou grande parte desse pensamento, porém ainda é necessário uma estrutura melhor para que esses pacientes e a família possam lidar melhor com essa situação. As visitas são uma inovação no campo de saúde mental, mas ainda precisa muito mais para da suporte ao paciente e os que convivem com ele. Inserir - los no convívio social, ensinar eles a pensar e ter autonomia é um papel não apenas dos familiares, mas de todos que fazem saúde.

\section{Considerações Finais}

Levando em conta as informações levantadas, e após uma análise crítica das entrevistas, foi percebido que os familiares realizam os cuidados básicos necessários com os pacientes encarcerados, mas não é suficiente para que possa libertar esses pacientes da situação de cárcere. Ainda que tenham consciência de que o cárcere é um atraso para o tratamento do paciente como também para a vida em seu meio social, os familiares relataram que a culpa para esta situação é do próprio paciente, por serem perigosos ou muitas vezes fugirem do seu cotidiano.

Após toda a análise dos dados neste trabalho, foi possível perceber que os usuários do CAPS e seus familiares sentem uma enorme necessidade das visitas domiciliares realizadas pela 
equipe. Os profissionais realizam as visitas respeitando o meio de convívio de cada família, orientando os cuidados e sempre os encorajando a melhor adequar-se a situação dos pacientes, para que os mesmos saiam do convívio isolado e passe a coletividade. Portanto 3 dos familiares relataram conseguir o semi-cárcere com esses pacientes levando-os até para o banho de sol diariamente.

Pode-se verificar também diante das afirmações que o CAPS está inserindo esse dispositivo, a visita domiciliar, há algum tempo, porém, mesmo orientados e encorajados, os familiares acreditam que essas visitas são realizadas apenas com intuito de cuidar do paciente, quando na verdade a intenção é um cuidado humanizado com todos os membros da família para que possam ter um suporte a mais para melhor lidar com a situação, uma vez que o paciente com transtorno mental dispõe de cuidados especiais.

As principais dificuldades relatadas pelos sujeitos da pesquisa em relação a esses pacientes são financeiras e a dependência aos cuidadores. Era importante que os gestores investissem financeiramente visando um melhor atendimento das necessidades dos mesmos, já que é dispendioso demais ter um portador de transtorno psíquico em casa e estes muitas vezes estão impossibilitados de arcar com suas despesas.

Portanto, se faz importante maiores estudos acerca do assunto abordando os usuários do CAPS em situação de cárcere privado, para assim as mudanças da reforma psiquiátrica estarem mais presentes nos dispositivos. É necessário uma parceria entre Unidade Básica de Saúde e também outros dispositivos de saúde mental, para que juntos possam realizar um trabalho holístico com essas famílias. O transtorno é do paciente, mas os cuidados também têm que serem voltados para a família.

Dessa forma, pretende-se que este trabalho abra espaço para que os gestores e profissionais de saúde possam desempenhar melhor as mudanças da reforma psiquiátrica nos dias atuais, fazendo reflexões sobre os cuidados prestados a esses pacientes.

\section{Referências:}

ASSIS, S.; AVANCI, J. É possível prevenir a violência? Refletindo sobre risco, proteção, prevenção e promoção da saúde. In: NJAINE, K.; ASSIS, S.; CONSTANTINO, P. (Org). Impactos da violência na saúde. $2^{\mathrm{a}}$ ed. Rio de Janeiro: FIOCRUZ, 2009. 380p.

BARDIN, Laurence. Análise de conteúdo. Lisboa: Edições 70, 2002.

BORGES, C. F. ; BAPTISTA, T. W. F. O modelo assistencial em saúde mental no Brasil: a trajetória da construção política de 1990 a 2004. Cadernos de Saúde Pública. Vol. 24, nº 2, p. 456-468, 2008. 
BARROSO, S. M., BANDEIRA, M. E NASCIMENTO, E. Sobrecarga de familiares de pacientes psiquiátricos atendidos na rede pública. Revista de Psiquiatria Clínica. V. 34. N.6. p. 270-277, 2007.

BRASIL. Ministério da Saúde. Conselho Nacional de Saúde. Resolução nº 196, de 10 de Outubro de 1996. Brasília: Ministério da Saúde, 1996.

FLORIANI, C.A.; SCHRAMM, F.R. Atendimento domiciliar ao idoso: problema ou solução?. Cad. Saúde Pública, Rio de Janeiro. V.20. n.4. p.986-994, jul-ago, 2004;

KOGA, M.; FUREGATO, A.R. - Convivência com a pessoa esquizofrênica: sobrecarga familiar. Ciência, Cuidado e Saúde . v.1.n.1. p.75-79, 2002.

OMS. RELATÓRIO MUNDIAL DA SAÚDE. Saúde mental: nova concepção, nova esperança. Direcção-Geral da Saúde, 2002 / OMS. 1. a edição, Lisboa, Abril de 2002;

SCHRANK, G.; OLSCHOWSKY, A. O CAPS e as estratégias para a inserção da família. Rev. Esc. Enf. USP. São Paulo. V.42. n.1. p. 127-134, 2008.

\section{Como citar este artigo (Formato ISO):}

ALENCAR, F.S.; CAVAÇLCANTE, L.V.T.F..; LIMA, M.S.; OLIVEIRA, N.S; OLIVEIRA, G.F. Atendimento domiciliar em saúde mental ao usuário do CAPS.. Id on Line Revista de Psicologia, Novembro de 2013, vol.1, n.21, p.85-93. ISSN 1981-1189. 